\title{
Ecology of Matter and the Surface Design in the Leather Fashion Industry
}

\author{
Marlena Pop ${ }^{1 *}$, Carmen Gaidau ${ }^{2}$, Olga Niculescu ${ }^{3}$ and Traian Foiasi ${ }^{4}$ \\ ${ }^{1}$ Senior Researcher, National Research Institute for Textile and Leather, Romania \\ ${ }^{2}$ Head of the Leather Research Department, National Research Institute for Textile and Leather, Romania \\ ${ }^{3}$ Specialist in the leather finishing techniques and technologies, National Research Institute for Textile and Leather, Romania \\ ${ }^{4}$ Specialist in the footwear design for fashion, National Research Institute for Textile and Leather, Romania
}

*Corresponding author: Marlena Pop, Senior Researcher, National Research Institute for Textile and Leather (INCDTP), Bucharest, Romania.

Received Date: October 21, 2019

Published Date: October 29, 2019

\section{Abstract}

Leather is a natural and durable material, unmatched by any synthetic product in terms of hygienic and protective properties. The processing of the oldest fiber-based material used for man's clothing combines the highest knowledge in chemistry with traditional craftsmanship. Nowadays leather industry is directly related to meat consumption and declares that it is by definition a sustainable activity through reclaiming a valuable byproduct. The challenge regarding the leather processing sustainability involves important steps from raw material preservation through wet-white tanning and more ecological surface finishing by using nanomaterials.

Our contributions regarding the innovative processes for chromium salts reduction and elimination from hide and skin tanning will be presented. Ecological tanning of hides and skins will be approached with new ecological mineral tanning, vegetable and organic materials in view of cleaner wastewater releasing and more biodegradable leather design. The leather surface finishing will take into consideration the use of multifunctional nanoparticles for smart leathers or handmade painting on vegetable tanned leathers for creative industries.

Surface Design is an interface between material, technology and consumer, being both a scientific and technical interface and a socio-cultural one. In the fashion industry the added value is only reflected by an efficient surface design, but the Surface Design is not just a type of finish, it is an art-science act that, if well-known and coordinated, can be spectacular and sustainable at the same time.

Laboratory experiments conducted by interdisciplinary teams will highlight the structure of cultural sustainability in fashion products, associated with the scientific sustainability of leather chemistry oriented towards the ecology of materials. The whole approach is the result of research projects carried out in the institute together with the industry.

Keywords: Leather; Ecology; Surface design; Collaborative research

\section{Introduction}

Any production of objects, images, culture, energy, etc. uses matter existing in nature and generates useful and useless energy, loading the toxicity of the planet together with unused material residues, it can be said that sustainability of human concepts, products, processes and actions is not only necessary, but becomes mandatory. In future years there will be no production without sustainable technologies and products that, after consumption, will not be recycled or biodegradable. In the field of eco-design, ethical-fashion, green product, etc., the theme of sustainability is not just a trend but a constant research topic under all aspects of the human-product-technology-consumption-environment relationship, developing the circular economy, based on four pillars: environment, economy, social and culture [1].

The context of the pressure of environmental problems on the industries, the practice of calculating the carbon footprint of the product, as an indicator of LCA, the management of waste and orientation towards the development of circular economy, legitimize bringing into question consumption and its relation with the industry, the relation between the quantity of consumer goods and their value and quality. At the socio-cultural level, it is 
observed, at the consumer level, that the more ecological culture and awareness of the responsibility towards the environment, towards society and its own carbon footprint, the greater the attention paid to purchased products, green economy, eco-design, biotechnologies, etc. For consumer goods with personal impact and status, such as those in the fashion industry, life-style industry, interior design industry, multimedia, home appliances, furniture industry, creative industries etc., production sizing becomes more and more difficult without suitable tools for measuring the typology of consumption given that customization, of the demand for consumption culture and green knowledge are becoming permanent indicators of the market quality.

Developing research in product design and industrial design in the last years has enabled a more concrete assessment of relationships between science and design or technology and design, the innovative values and cultural meanings expressed by the product, as well as the result of the collaborative actions of the research teams. These collaborative actions are specific to interdisciplinary research, although, in general, people are more accustomed to cooperating than collaborating. The difference between the two types of actions is like the one between a puzzle and a Rubik's cube or, as the artists say, it is the difference between juxtaposition and mixture. While there is a lot of talk about creativity in the field of fashion, whether it is clothing, accessories, furniture or interior design, there are few collaborative teams working together to create a product, from research to design, technology or marketing. For environmentally friendly leather products, technological standards impose exclusive limitations on linear technological activities, which are absolutely necessary. The cooperation between design and marketing demonstrates that the durability of a leather product for fashion is built from the parameters of leather manufacture, functionality, social status and aesthetic parameters [2]. This is why written labels, explanations and demonstrations are required to attest to the authenticity of the product. If all these indications are set aside, the leather product, through its appearance, texture, touch, smell, should suggest the comfort indicated in all written specifications. Since a garment, a bag, shoe or coat cannot be destroyed, the entire expression of durability is given by the surface of the material. That is why leather surface design research is necessary and requires collaborative research, being an interdisciplinary field by definition.

Surface design is an interdisciplinary working environment, for the section of $0.6-1.5 \mathrm{~mm}$ in the structure of materials. This environment called finishing, texture, touch, in which materials science is combined with the technologies of hide processing and finishing, the theory and practice of product design, in which the cultural sustainability component clearly expresses the aesthetic and socio-human value of the product, represents, basically, the motivation of a purchase decision. Thus, Surface Design is an interface between material, technology and consumer, being both a scientific and technical interface, as well as a socio-cultural one. Leather is a natural and durable material, unmatched by any synthetic product in terms of hygienic and protective properties. On the substrate of a raw, ecological material, by its nature, processing technologies work by bringing a high-quality material structure to the semi-processed stage for creative industries where the fashion industry is an important cultural peak. Processing of the oldest fiber-based material used for human clothing combines the highest knowledge in chemistry with the traditional craft or artistic performance. The challenge regarding the sustainability of leather processing involves important steps from the conservation of the raw materials to wet finishing and the more ecological finishing of the surface through the use of nanomaterials. The document presents the research in the surface design technology, chemical nanotechnology structure of the leather and particular aspects related to the cultural and technical sustainability of leather products in the fashion.

\section{Surface Design as a Process and Leather Texture as Product, from a Technical Perspective}

Leather processing is one of man's oldest tasks. Yesterday, just as today, the raw material was the hides and skins of domestic and wild animals from which various types of footwear, clothing, belts and other household items were made. The processing operations involve the transformation of rough, easily degradable hide into finished leather - a stable product, used to produce a wide range of items with various uses. Leather tanning can be carried out with very different substances in terms of chemistry - mineral salts, vegetable tannins, syntans, fats, aldehydes - with a complex structure and which behave differently from skin proteins. Chromium tanning is the most widespread process in the world $(90 \%$ of processed leather). The vegetable tanning process is not considered as an alternative to the chrome salt tanning process, because they are completely different processes that yield different products, which are highly appreciated by artists and environmentalists for their natural qualities, both in structure as well as in texture, and which can outline better directives in slow fashion.

The current ecological standards impose strict regulations in technological processes with hexavalent $\mathrm{Cr}$, so that the carbon footprint of all processes, both technological and social, is as small as possible. In this context, the wet finishing of natural leathers is achieved using auxiliary retaining materials based on acrylic polymers, tannin resins, synthetic and vegetable tannins, fat liquoring oils, and dyes for dyeing, giving natural leathers the following characteristics: softness, dimensional stability, dyes in uniform colors.

\section{Finishing by coating}

This is the last operation in leather processing, on which the appearance and value of the finished product depends to a large extent. It aims to beautify, give a glossy and pleasant touch, cover defects and form a surface layer that protects the leather during wear. The coating finish also improves the resistance to external factors (light, rubbing, scratches, water). Current directions in the field of leather processing are aimed at improving the technological processes, processing machines and auxiliary materials used in order to obtain finished leather that corresponds to the quality, 
ecological and fashion requirements. Leather finishes stand out by the novelty of their effects. Thus, leather with contrasting, antique, cracked, wrinkled, pleated, polished, printed, glossy, matte, pearly effects, with a silky or waxy touch, aniline, semi aniline, hydrophobicized, in a very varied color range, or imitations of other animals' skins, which can be made from pressed bovine leather imitating reptile (crocodile, python, iguana), ostrich or kangaroo skin, if finished properly, with materials that convey the desired aesthetic characteristics, is very fashionable. The main characteristics imposed on finished leather are color, gloss, matting, touch, resistance to repeated bending, aesthetic appearance, printing, water resistance, water vapor permeability, light fastness (white leather). Almost all types of hides (bovine) and skins (sheep, goats, reptiles, fish, etc.) can be finished in various assortments for footwear, clothing, leather goods, furniture upholstery, cars, book binding, etc. [3].

Leather is finished using dispersed systems in which the following auxiliary materials are used: pigments, binders, natural and synthetic waxes, preservatives, plasticizers, thickening agents, fillers, odorizing substances, penetrators, solvents, ant fungicides or anti bactericides. Natural leather is finished by applying the dispersed finishing systems on the dermal substrate by spraying or using ecological finishing machines with rollers (Roll-Coating and Reverse-Coating). The types of finishes differ depending on the work procedures or the desired effects.

A large number of technologies are used in leather finishing, yielding different characteristics of the finished product. Varying the components or working methods, even the same finishing process can lead to different gloss, matting or coating effects, as well as different characteristics of the film's texture and softness [4].

\section{Auxiliaries used in disperse finishing systems}

The elaboration of the formulations of dispersed filmforming systems to finish leather must take into account the final characteristics of the layer in the whole dermal surface coating film (appearance, thickness, physical-mechanical resistance, fashion) $[6,7]$.

Pigments: Issues currently affecting the leather finishing industry include bans on the use of heavy metal salts (chromium, cadmium, lead, cobalt, mercury, nickel) in pigment pastes, ethoxylated alkylphenols as dispersing agents for waxes, formaldehyde and other toxic crosslinkers. Environmental and toxicity concerns have led to new alternatives for the finishing auxiliary's industry. Pigments are inorganic or organic chemical compounds that constitute the dye base of coating paints. In order to be used for leather finishing, the pigments must have certain characteristics, of which the most important are: light resistance, the action of atmospheric agents and high temperatures, bright and vivid color, without tanning, high coverage power, high dispersion degree, compatibility with other coatings. Organic pigments give brighter, livelier and more intense colors than inorganic ones, but the disadvantage is that they have low coverage power and produce a tanning effect. To increase the coating power, organic pigments are most often used in combination with inorganic ones [8,9].

Binders: Binders are film-forming macromolecular compounds used in all stages of finishing to give leather flexibility, adhesion and resistance to wear and to external factors. The composition of leather surface finishing systems includes acrylic, polyurethane, butadiene and nitrocellulose binders. Depending on molar masses and hardness, binders are used in various finishing coats (basecoat or dressing) to obtain the desired finish.

Polymers of acrylic acid esters are solid, transparent, colorless, resistant to water, alcohol, light and acids, are elastic and have a high degree of adhesion. They are used in all stages of finishing, from impregnation to the final layer, and generally provide a film with good flexibility, adhesion, and resistance to light. The films obtained from polyesters of acrylic acid are very elastic, thermoplastic, resistant to light, repeated bending and ageing.

Polyurethane binders are poly addition compounds, obtained by the reaction of isocyanates and polyols. The aliphatic ones are most commonly used, giving leather the best physical and mechanical properties. The aromatic ones are less used, as the resistance to light of films is poor. An important step that stimulated the development of new technologies to obtain polyurethanes was perfecting aqueous polyurethane dispersions. These yield soft and elastic leather, such as Napa for furniture upholstery and footwear uppers.

Butadiene binders have high coverage power, but reduced light fastness, and are particularly used in finishing polished and split leather.

Protein binders may be based on casein, albumin and synthetic polyamides. They are used on a large scale to obtain glossy finishes that imitate patent leather $[10,11]$.

In the composition of coating dyes are used binders and lustre agents based on natural products enhanced by chemical treatment (Ethoxylated casein) [12].

Aqueous nitrocellulose emulsions are oil-in-water emulsions in which the dispersed phase contains cellulose nitrate solution, optionally in a mixture of solvents, and the dispersed phase is water. They are used in the final finishing coat. Because of their low resistance to light, they are not used in finishing white leather or leather for upholstery.

Waxes: Both natural and synthetic wax is used in natural leather finishing in order to reduce the stickiness of thermoplastic binders and give a nice touch and color darkening effects (in waxed leather assortments, which are fashionable).

Waxes are esters of the higher monocarboxylic acids with higher primary monohydroxyl alcohols. Natural waxes, such as beeswax, are mixtures of several esters, with varying amounts of acids, free alcohols and alkanes. Synthetic waxes are mixtures of esters of higher fatty acids (normal chain monocarboxylic acids and even carbon atoms) with normal monohydroxyl (C22) higher alcohols, 
which are emulsified with nonionic emulsifiers (ethoxylated fatty alcohols).

\section{Making bovine and sheep skin assortments}

Next, various assortments of bovine and sheep skin (with or without fur) are presented for garments, and their main characteristics.
Sets of bovine leatherwith slightly polishedfaceand finished with a coating film, smooth and pressed, color. The leather assortments are obtained by tanning cattle hide with basic chromium salts and processing by means of wet finishing operations (neutralization, retaining, dyeing, fat liquoring), mechanical and dry finishing operations by coating with smooth, pressed film (Figure 1).

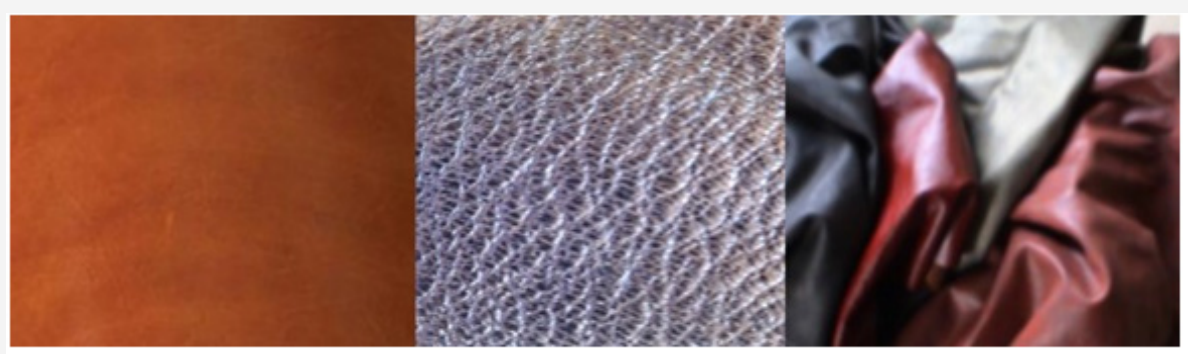

Figure 1: Leather finishing samples made in INCDTP-ICPI, Bucharest, in the projects of Dr Olga Niculescu.

Assortments of bovine leather finished with coating film, reptile pattern embossing, two-color leathers, used to make footwear and leather goods. The vegetable-tanned leather assortments are obtained by tanning cattle hide, with basic chromium salts or with vegetable tannins, and processing by means of wet finishing operations, mechanical operations and dry finishing by coating with finishing film, and reptile pattern embossing (Figure 2).

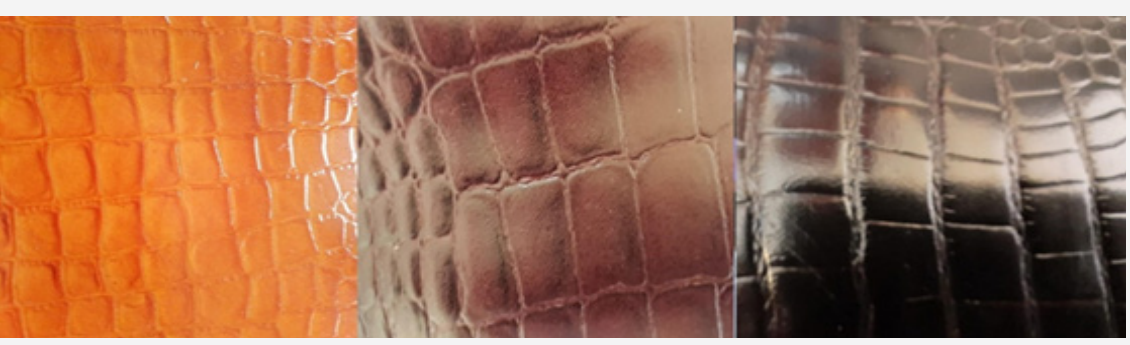

Figure 2: Leather finishing samples made in INCDTP-ICPI, Bucharest, in the projects of Dr Olga Niculescu.

Assortments of bovine leather finished with a coating film, smooth, with aesthetic stains, used to make leather goods and office supplies. The leather assortments are obtained by tanning cattle hide, with basic chromium salts and processing by means of wet finishing operations (neutralization, retaining, dyeing, fat liquoring), mechanical operations and dry finishing by coating with finishing film, with aesthetic staining using machines with spray guns (Figure 3).

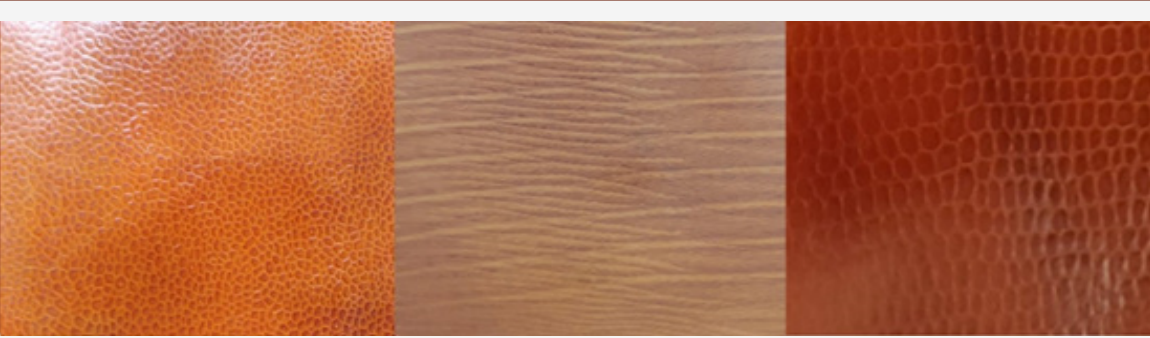

Figure 3: Leather finishing samples made in INCDTP-ICPI, Bucharest, in the projects of Dr Olga Niculescu.

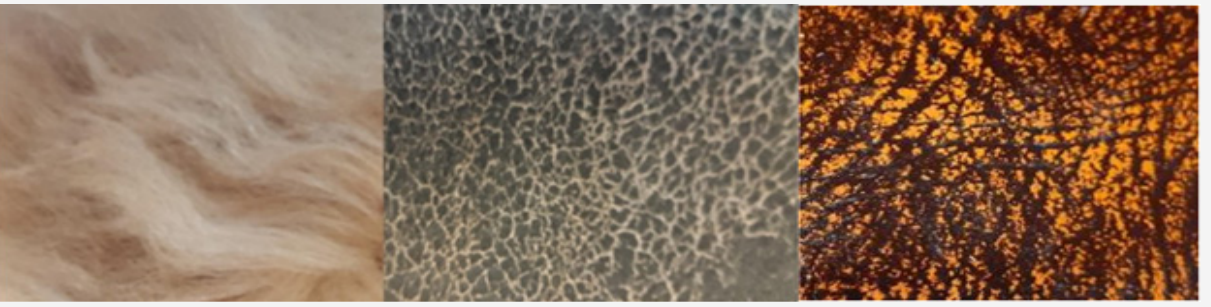

Figure 4: Leather finishing samples made in INCDTP-ICPI, Bucharest, in the projects of Dr Olga Niculescu. 
Assortments of sheepskin finished with a coating film, perfumed, used to make garments. The fur sheepskin assortments are obtained by tanning the sheepskin with basic chromium salts, or with synthetic agents based on phenol sulfonic acids and aromatic oxisulfones, and processing by means of wet finishing operations, mechanical operations and finishing with scented Napa finishing film (Figure 4).

\section{The Scientific Approach to a Surface Design - Emerging Finishing Experiments}

Leather making converts a renewable resource into a highly valuable, durable and safe material and thus provides employment of a significant scale in several downstream industries. Transformation of raw hides and skins into leather applying the Best Available Technologies (BAT) and following the highest environmental standards should ensure the position of leather as the preferred, sustainable material [13].

\section{Sheepskin treated with silver nanoparticles}

This study has shown a novel way to prepare antibacterial sheepskin with silver nanoparticles as an antibacterial agent. The UV-vis absorption spectroscopy indicated nearly all of the silver nanoparticles were adsorbed by the sheepskin in this way. The SEM images confirmed that the silver particles attached on the surface of the sheepskin. The results of antibacterial study showed that the treated sheepskin had an antibacterial inhibition of $99.9 \%$ against Escherichia coli and Staphylococcus aureus, even after 6 cycles of perspiration treatment, the sheepskin still exhibited a durable antibacterial effect with the inhibition above $79.4 \%$ and $67.1 \%$ for the leather and the wool, respectively. Thus, this study has presented an eco-friendly alternative for the antibacterial treatment of sheepskin without organic compounds (Figure 5) [14].
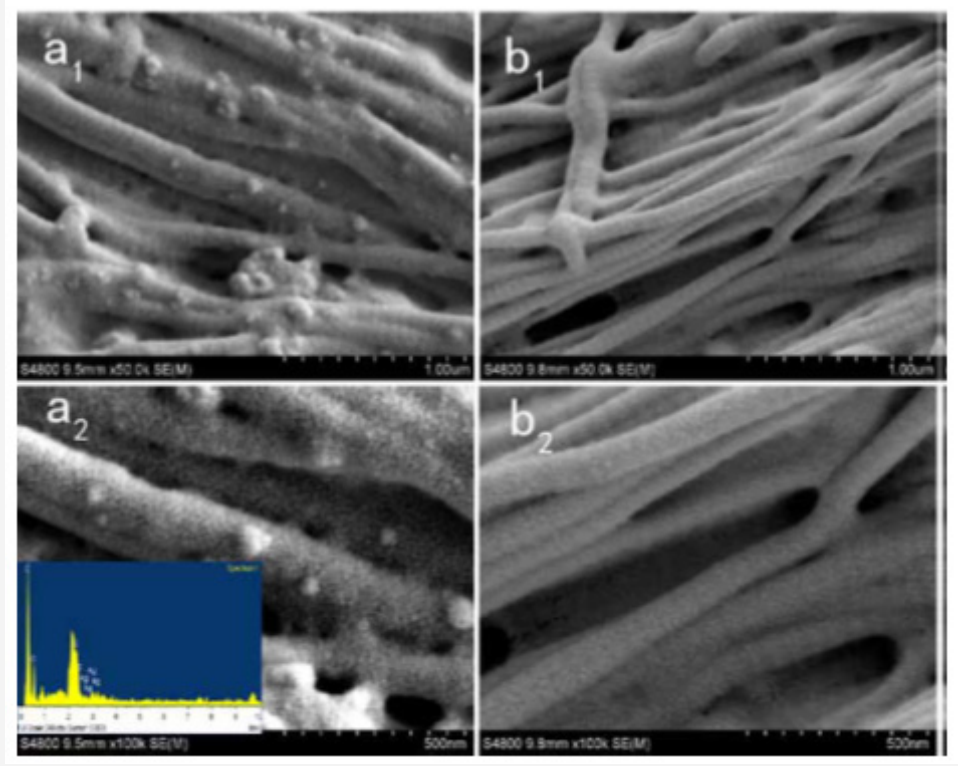

Figure 5: SEM images of the leather with silver nanoparticles (a1, a2) and control (b1, b2). EDS analysis shows peaks of silver (small panel) (Weite Yang, Xuan Wang, Ying Gong, Hui Li, Wuyong Chen and Carmen Gaidau, JALCA, VOL. 107, 2012).

\section{Silver nanoparticle finish for self-cleaning under visible light}

The leather surface covered with Ag-N-TiO 2 NPs showed enhanced self-cleaning and antimicrobial properties, increasing the leather durability and usability and paving the way for designing new nanoparticles with multiple functionalities. Silver nanoparticles were deposited on $\mathrm{TiO}_{2} \mathrm{NPs}$ and $\mathrm{N}-\mathrm{TiO}_{2}$ NPs by electrochemical method and showed advanced photoinduced catalytic properties in the visible domain. The particle size increased by silver deposition from $20 \mathrm{~nm}$ and $25 \mathrm{~nm}$ for $\mathrm{TiO}_{2} \mathrm{NPs}$ and $\mathrm{N}-\mathrm{TiO}_{2} \mathrm{NPs}$ to $31 \mathrm{~nm}$ and 40nm for $\mathrm{Ag}_{-} \mathrm{TiO}_{2} \mathrm{NPs}$ and $\mathrm{Ag}-\mathrm{N}-\mathrm{TiO}_{2} \mathrm{NPs}$ according to transmission electron microscopy analyses. The water dispersions of $\mathrm{Ag}_{-}-\mathrm{TiO}_{2}$ $\mathrm{NPs}$ and $\mathrm{Ag}-\mathrm{N}-\mathrm{TiO}_{2}$ NPs were stable with Zeta potential of $-41.4 \mathrm{mV}$ to $-47.4 \mathrm{mV}$. Diffuse reflectance spectra of $\mathrm{Ag}^{-\mathrm{TiO}_{2}} \mathrm{NPs}$ and $\mathrm{Ag}-\mathrm{N}-$ $\mathrm{TiO}_{2}$ NPs shifted to the visible domain as compared to $\mathrm{TiO}_{2} \mathrm{NPs}$. Photocatalytic properties of silver deposited on $\mathrm{TiO}_{2} \mathrm{NPs}$ and $\mathrm{N}-\mathrm{TiO}_{2}$ NPs tested on Orange II dye solution under UV and visible light exposure were investigated for different silver concentrations and resulted in the selection of the $0.5 \%$ concentration as the most efficient in visible light. The enhanced photocatalytic properties in the visible light domain were confirmed under leather surface through self-cleaning stains of ball pen ink, Orange II and methylene blue dyes that were recorded for leather surfaces treated with Ag$\mathrm{N}-\mathrm{TiO}_{2}$ NPs. The antimicrobial resistance of leather surface treated with Ag-N-TiO 2 NPs was excellent against Candida albicans ATCC 26790, Candida albicans 1760 and good against Epidermophyton floccosum. The leather surface sensitivity tests upon direct contact with Escherichia coli ATCC 25922 and Staphylococcus aureus ATCC 25923 proved to be resistant for both treatments based on Ag$\mathrm{TiO}_{2}$ and $\mathrm{Ag}-\mathrm{N}-\mathrm{TiO}_{2}$ nanoparticles. The improved antimicrobial sensitivity and resistance as well as the self-cleaning effects under visible light were attributed to the photocatalytic induced hydrophilic properties on leather surface treated with silver electrochemically deposited on $\mathrm{N}^{-\mathrm{TiO}}{ }_{2} \mathrm{NPs}$ (Figure 6). 

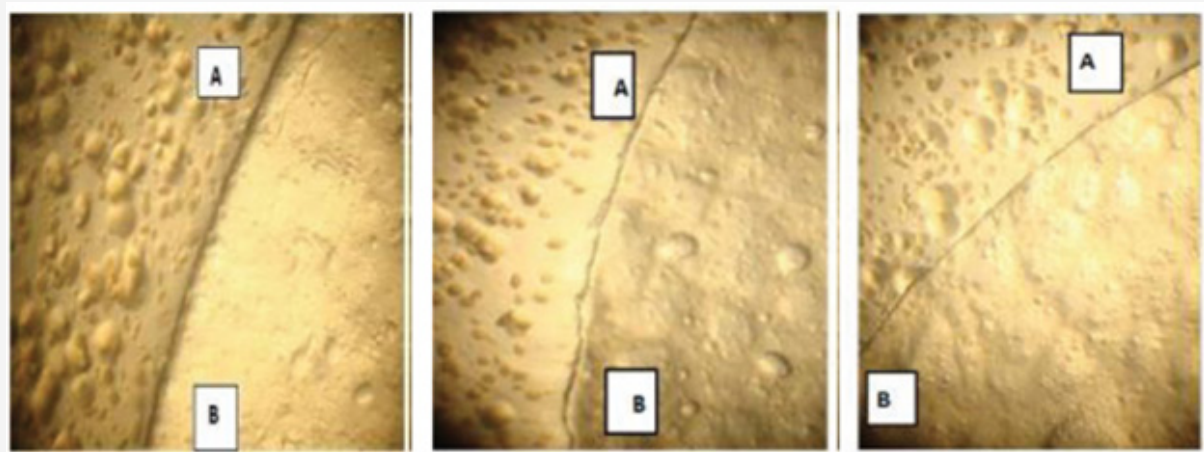

Figure 6: The sensitivity test of leather surfaces against Escherichia coli ATCC 25922 (a, b) and Staphylococcus aureus ATCC25923(c) [5].

\section{Smart leather processing with new nanomaterials}

Many recent studies were devoted to smart leather processing with new nanomaterials with potential to be used in low concentrations for new properties development or as alternative to volatile organic compounds. The impact of new materials and processed products on human health and environment are of high interest the more they are at the nano scale. The use of commercial nanoparticles with particle size under $8 \mathrm{~nm}$ was found to be efficient in terms of antimicrobial properties and with photocatalytic potential for leather surface finishing [1]. The wearing simulation tests and cytotoxic logical evaluation on human skin cells showed that the released concentrations of nanoparticles can be managed by leather processing below cytotoxic logical risk limits. Nanoparticles offer a great area for innovation because their properties differ significantly from ion or bulk materials through their unique chemical, electrical, optical, and biological activity which are mainly determined by the size, shape, composition, crystallinity or other structural properties. The studies regarding the antimicrobial properties of nanoparticles are the most numerous due to their efficiency on a large spectrum of bacteria and fungi.
Silver, zinc oxide, titanium oxide, silica, carbon-based nanoparticles or compounds of these showed promising functionalities regarding antimicrobial, photocatalytic, conductive properties or heat/fire resistance. The potential of nanoparticles is still under research for leather industry and no commercial dedicated products are on the market. The balance between efficiency and added cost can be improved by multifunctional properties generation under leather surface. Another limitation is the lack of information regarding the potential risk associated with specific nanomaterials and the need to evaluate every kind of treated material. Our previous studies showed that Nano silver [15] doped nitrogen-titanium dioxide (Ag/ $\mathrm{NTiO}_{2}$ ) has enhanced antimicrobial and photocatalytic properties and cytotoxicity [16] tests on lung and skin human cells found that the concentration risk limits are of $500 \mu \mathrm{g} / \mathrm{mL}$ [8] which is very high as compared to other reference [17] with values of $10-25 \mu \mathrm{g} / \mathrm{mL}$. We have investigated the multifunctional properties of leather surface finished with commercial $\mathrm{Ag} / \mathrm{TiO}_{2}$ nanoparticles in solution, the scenarios regarding the potential nanoparticle releasing in wearing conditions and the potential nanoparticles cytotoxicity impact on human skin cells (Figure 7) [18].

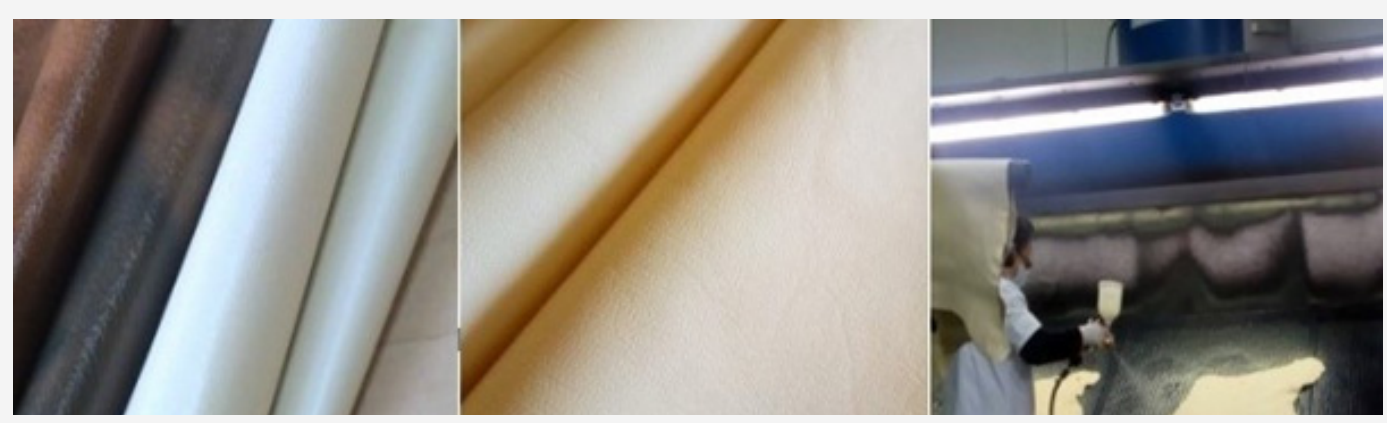

Figure 7: Leather finishing by spraying with Ag/TiO2 nanoparticles in INCDTP-ICPI Bucharest, Romania (Dr Carmen Gaidau) project No.15/2015 under the frame of the ERA-NET for a Safe Implementation of Innovative Nanoscience and Nanotechnology program and project No. 44 PHYS for TEL/2018 within PNCDI III funded by Romanian Ministry of research and Innovation, CCCDI-UEFISCDI.].

\section{Surface Design from a Humanistic Perspective}

The literature shows that the attention paid to research studies in product design has focused on investigating the interdisciplinary relations among design-innovation-competitive advantage, as well as among design-science-technology. It is shown that design is a strategic tool, capable of generating competitive advantage by itself and suggest sustainability. This type of relationship is evident in surface design, because if the emphasis is on one of the directions of approaching the surface, the final product will be technically dominant, with a classic commercial value; if the emphasis is on the scientific emergence, then the product will have a technical image, but suggestive of creativity; and if the design is dominant then the product may be an artistic leather, or an apparently technical one, 
or with an obvious eco-cultural semiotics, ethno-contemporary or a post-industrial symbolism. What remains important is the relationship between the ecological structure - the manufacturing technology - the cultural ecodesign, that are the real foundation for the product to be environmentally friendly. In many specialized studies designs is defined in a different way. Thus, it appears as an understanding of Styling, Thinking - a way of thinking about a product or as Meaning - an activity that generates meaning. For design structuralists, it remains essentially as form, because only "form follows function" Sullivan dicton, and this generates styling. The second conception of design refers to design thinking that has the capacity to change the environment, transforming it into an ecosystem, being "a better way of thinking" [19]. The third approach says that "Design can be defined as the human capacity to shape and make our environment in ways without precedent in nature, to serve our needs and give meaning to our lives" $[8,10]$. Approaching design as a strategic tool for innovation and meaning can be taken into account in interdisciplinary research. This will be the approach adopted in this paper.

In order to shape surface design as an interdisciplinary activity it is necessary to remember that it defines the texture created by humans, just as people call texture any surface of objects and beings in nature. "Organic life on earth is a chaos of ever-changing textures" [20]. Any modification of the textures can be done by man through touch, visualization or mechanical and chemical processing. The appearance of the anthropic products is given by the texture analyzed through interdisciplinary or technological research and developed by surface design, being a linear chain of finishing and design technologies for fashion, for example. In fashion products made of textile or leather, the texture is the element that supports the artistic and ecodesign message as well as cultural, ecological or innovative meaning. Surface design of texture is the essential aspects of clothing design. Theoretical and practical studies on the texture of fashion products have focused on the typology of textures depending on the areas (metals, ceramics, textiles, leather etc.), sensory typology of texture memory (soft, smooth, hard, rough etc.), texture spatiality (2D-3D), texture brightness (matte, glossy, iridescent, fluorescent, neon etc.), technological aspects of leather texture, for example: mirror, reptile print, polished, film-coated, velvety etc. From the designer's perspective, surface design can address texture in terms of artistic techniques, therefore visually, or in terms of technical ones with aesthetic effects that can be exploited innovatively, or scientifically, when there is a collaborative art-science project.

From the designer's perspective, the textures can be naturally macroscopic. These can be inspirational in creating a texture, finding numerous inspiration sources in nature, heritage or technological artifacts. They can be naturally microscopic because the nanometric universe of biological as well as inorganic matter is immeasurable. This represents an inexhaustible inspirational source of great interest in surface design research. Textures can be visual, from an artistic point of view, and their characteristics are given by thematic, descriptive, symbolic or inspirational subjects in the visual arts. The tactile texture is the one that has a 3D surface specific to some artistic techniques, to a plastic technical style, such as brush stroke, pressing in animal print. In visual art and design, "texture defines the surface of the work created". Surface design is the process by means of which chemical, mechanical or artistic modeling of the surfaces leads to innovative, creative or simply original textures. It "makes the surface or substance feel or look different in color or shape, regardless of whether the surface is rough, smooth, robust or silky" [21]. The artistic and technical characteristics of textures evolve at the same time and in the same direction with art and design trends, from the real texture of the materials to the innovative, artistic or technical texture.

Visual texture is the sensation perceived from the surface of the materials or artificial creations, defined by Pipes as something "created by the artist's hand", which specifies the two-dimensional surface texture involved in art and design [21]. There is no tactile sense that can be perceived from the visual texture which is an important and developable element in two-dimensional fields. Visual texture shows a creative activity performed by artists and designers using their imagination. The types of simulated texture, abstract texture and innovative texture are divisions in creating visual texture.

Simulated texture is a surface that looks like a real substance but is actually unreal [22]. The art style of "trompe l'oeil" (Fr), which means "deceiving the eye", is an extreme result of the visual texture created by simulating real textures. Simulated texture can trigger memories of a real object when people see simulated images. Such a texture can suggest a certain sensation of a substance without the sense of touch. Photography is a way to simulate textures, in which everything has its own textural appearance with faint and cast shadows. However, artists and designers are not content to simply reproduce images with existing objects. Many new visual textures are created to abstract real world textures or were invented to describe the imagination of a creator.

The abstract texture, as the name suggests, is created through abstract work and modified with a hint of the original texture to meet the creator's intention. Abstraction mainly involves visual simplification and sometimes exaggeration. The abstract texture is the symbolization of an original object and has the function of decoration and can tell its observers what they see [23].

In the Figure 8 is a decorative manual painting, with semiotic and chromatic elements specific to the Dacian shields of the $1^{\text {st }}$ century B.C. The relationship between the vegetal structure of the skin, reminiscent of tanning with tannins, so specific to the Dacians, is made for a piece of wooden furniture with patina, reminiscent of our heritage.

In the Figure 9 the theme of rain is presented, both by the technical archetype of rendering the splashes of water on the skin, as well as by the rain symbolism, in Roman mythology. The "Paparuda" archetype is the symbol of rain dance. 
In the field of fashion, changing textures through artistic techniques of printing, profiling, pressing, mixed techniques, through innovative concepts of chromatics, graphics, meaning and message, leads to the development of a new aesthetic ideal, a fashion theme or an original fashion project. This transforms any texture created in the field of surface design into a fashionable commercial product.

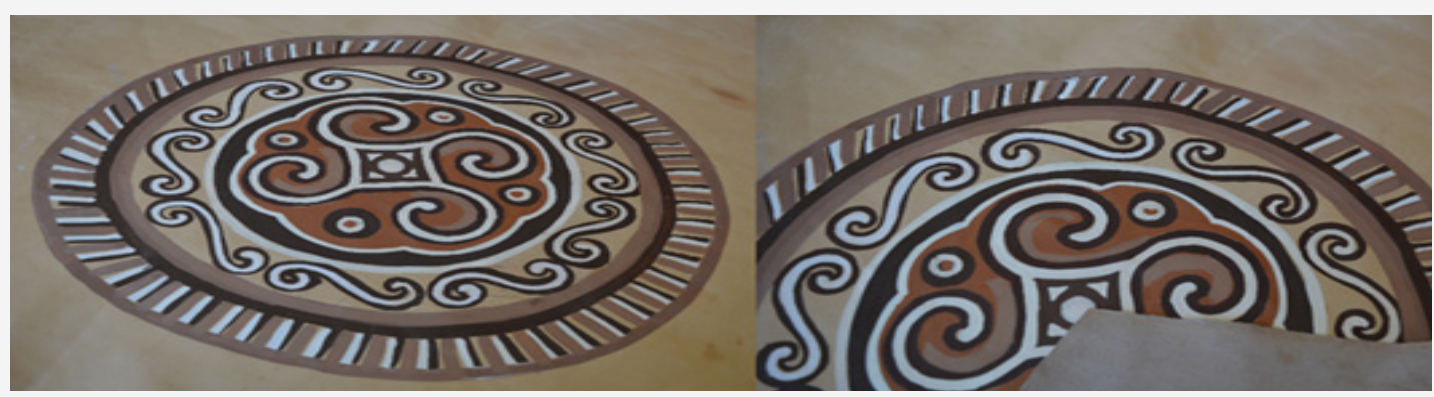

Figure 8: Hand painting with semiotics and Dacian symbolism, specific to the battle shields from the $1^{\text {st }}$ century B.C., on vegetable tanned leather support, in Dacian technique. Author: Dr Marlena POP.

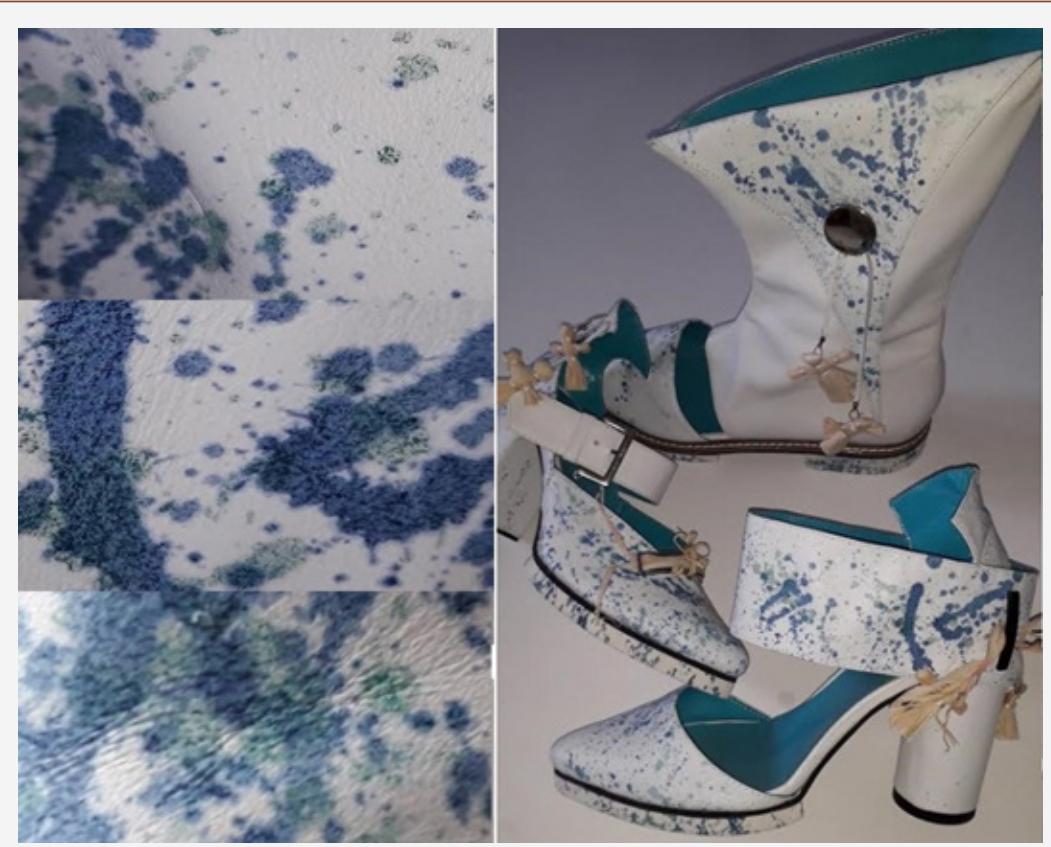

Figure 9: Hand painting on eco-friendly chrome leather holder and 3 pieces from the author's footwear fashion collection for summer 2019 , entitled "Paparude". Author: Traian Foiasi.

\section{Conclusion}

The cultural sustainability of a product is the synergistic effect of the relation between the cultural identity heritage value of the artistic or design theme approached by the designers, cultural values of the author, brand, ethnic or nation and the use of the aesthetic and ecological material, supports necessary to express it in a new product concept $[24,25]$.

The global sustainability of products represents the coexistence of scientific, technical and cultural sustainability parameters, which, in the case of leather, through its ecological structure, involves modern finishing technologies and the eco concept of surface design [26].

Developing sustainability of leather processing technologies implies the creation of an innovative technical niche that will highlight the sustainable scientific and cultural aspects.
Although the aesthetic and cultural elements are dominant in surface design, leather fashion products, made in the slow fashion manner, can be ecological if the technical and scientific matrix of the material structure can be shown to be ecological.

Smart leather processing with new nanomaterials outlines the emerging directions of collaborative surface-design skin research.

Surface design of the leather product for fashion is a field of sustainable design if a practice of interdisciplinary collaborative research between chemistry-technology-design is developed.

Through the scientific research projects presented in this article, projects that have approached surface design from three perspectives: innovation in leather finishing for the fashion industry, nanotechnologies for health and aesthetics through ecological structures of leather and artistic experiments in ecological leather surface design for the luxury furniture and 
fashion industry, we have attempted to show that the cultural sustainability and ecological support of leather are compatible with the directions of development of the consumer's demands regarding the contemporary fashion product.

\section{Acknowledgment}

This scientific paper is funded by the Ministry of Research and Innovation within Program 1 - Development of the national RD system, Subprogram 1.2 - Institutional Performance - RDI excellence funding projects, Contract no. 6PFE/2018.

\section{Conflict of Interest}

Authors declare no conflict of interest.

\section{References}

1. (2011) Eco-Design: Life Cycle analyses show that energy is a key factor for the environmental impact of leather and might save money. IULTCS Congress.

2. Burdujan J, Kral I (2015) The framework for sustainable leather manufacture. United Nations Industrial Development Organization.

3. Krutyakov YA, Kudrinskii AA, Olenin AY, Lisichkin GV (2010) Synthesis of highly stable silver colloids stabilized with water soluble sulfonated polyaniline. Applied Surface Science 256(23): 7037-7042.

4. Lee KJ, Jun BH, Choi J, Lee YI, Joung J, et al. (2007) Environmentally friendly synthesis of organic soluble silver nanoparticles for printed electronics. J Nanotechnology 18(33).

5. Gaidau C, Petica A, Ignat M, Iordache O, Ditu LM, et al. (2016) Enhanced photocatalysts based on $\mathrm{Ag}-\mathrm{TiO}_{2}$ and $\mathrm{Ag}-\mathrm{N}-\mathrm{TiO}_{2}$ nanoparticles for multifunctional leather surface coating. Open Chem 14(1): 383-392.

6. Heidemann E (1994) Fundamentals of Leather Manufacturing. Eduard Roether KG Druckerei und Verlag, Darmstadt.

7. Hertenstein JH, Platt MB, Veryzer RW (2005) The Impact of Industrial Design Effectiveness on Corporate Financial Performance. Journal of Product Innovation Management 22(1): 3-21.

8. Le AT, Huy PT, Tam PD, Huy TQ Cam PD, et al. (2010) Green synthesis of finely dispersed highly bactericidal silver nanoparticles via modified Tollens technique. Current Applied Physics 10(3): 910-916.

9. Özgunay H, Yilmaz O, DandarU, Çolak S, Zengin G, et al. (2016) The effect of valonea and henna treatment and post mordanting on CR (VI) and free formaldehyde formation in leather. Textile and Apparel 26: 327-334.

10. Niculescu O, Mendea F (2019) Inorganic pigment pastes for natural leather finishing. OSIM Patent A/ 130001/.

11. Niculescu O, Tonea RA, Tonea S (2019) Insecticide and scenting composition for the treatment of natural fur and fur goods. OSIM Patent A/ 130692/.
12. Niculescu O, Coara Gh, Chelaru C, Gurau D (2018) New products based on essential oils for finishing natural leathers with antifungal performances. The $7^{\text {th }}$ International Conference on Advanced Materials and Systems, Bucharest, Romania.

13. Niculescu O, Leca M, Staicu T, Moldovan Z, Chelaru C, et al. (2015) Obtaining and Characterization of Some Ecologic Pigment Pastes for Finishing Natural Leather and Furs. Revista de Chimie, Bukarest 66(9): 1278-1281.

14. Chudasama B, Vala AK, Andharya N, Mehta R, Upadhyay R (2010) Highly bacterial resistant silver nanoparticles: synthesis and antibacterial activities. Journal of Nanoparticle Research 12(5): 1677-1685.

15. Gaidau C, Petica A, Trandafir V, Ciobanu C, Martinescu T (2009) Nano silver application for collagen-based materials treatment. The $\mathrm{XXX}^{\text {th }}$ International Congress IULTCS Beijing, China.

16. Rebleanu D, Gaidau C, Voicu G, Constantinescu CA, Mansilla Sánchez C, et al. (2019) The impact of photocatalytic $\mathrm{Ag} / \mathrm{TiO}_{2}$ and $\mathrm{Ag} / \mathrm{N}-\mathrm{TiO}_{2}$ nanoparticles on human keratinocytes and epithelial lung cells. Toxicology 416: 30-43.

17. Hedberg YS, Liden C, Wallinder IO (2014) Correlation between Bulk and Surface Chemistry of Cr-Tanned Leather and the Release of Cr (III) and $\mathrm{Cr}$ (VI). Journal of Hazard Materials 280: 654-661.

18. Gaidau C, Calin M, Rebleanu D, Constantinescu C (2019) Added functions of leather surface by $\mathrm{Ag} / \mathrm{TIO}_{2}$ nanoparticles use and some considerations on their cytotoxicity. IULTCS Congress, Dresden, Germany.

19. Hekkert P (2006) Design aesthetics: principles of pleasures in design. Psychology Science 48(2): 157-172.

20. Hilliard E, Cliff S (2002) Fabric: The Fired Earth Book of Natural Texture. Pavilion Books.

21. Gong L, Shin J (2013) The innovative application of surface texture in fashion and textile design. Fashion \& Textile Research Journal 15(3): 336-346.

22. Okvirk O, Stinson RE, Wigg PR, Bone RO, Cayton DL (2012) Art Fundamentals: Theory and Practice. $12^{\text {th }}(\mathrm{edn})$, McGraw-Hill Education, New York, USA, p. 336.

23. Andor B, Tischer AA, Berceanu-Vaduva D, Lazureanu V, Cheveresan A, et al. (2019) Antimicrobial activity and cytotoxic effect on gingival cells of silver nanoparticles obtained by biosynthesis Rev Chim 70(3): 781-783.

24. Pop M, Manea I, Andronache B (2018) Cultural Identity in Product Design of Fashion Technology-Tools and Method, proceedings, The $7^{\text {th }}$ International Conference on Advanced Materials and Systems, Bucharest, Romania.

25. Pop M, Toma S, Frigy N, Pop AM (2018) Cultural work instruments in fashion technology -practical method of generating emotional design. Journal of Textile Science \& Fashion Technology 1(1): 1-7.

26. Pop M, HoratauD (2019) Cultural sustainability and archetype in creative textile design, The Fourteenth International Conference on The Arts in Society, Portugal: 19-21. 